\title{
ПЕДАГОГИКА
}

УДК 336.563.1:378.1:008(571.150)-057.87

DOI: $10.32340 / 2414-9101-2021-4-53-59$

Я. А. Ивонина, кандидат исторических наук Алтайский государственный институт культуры (Барнаул, Россия) yana-ol@mail.ru

\section{РАЗВИТИЕ ПРОЕКТНОЙ КУЛЬТУРЫ У МАГИСТРАНТОВ НАПРАВЛЕНИЯ ПОД- ГОТОВКИ «СОЦИАЛЬНО-КУЛЬТУРНАЯ ДЕЯТЕЛЬНОСТЬ» (НА ПРИМЕРЕ АЛТАЙСКОГО ГОСУДАРСТВЕННОГО ИНСТИТУТА КУЛЬТУРЫ (БАРНАУЛ, РОССИЯ))}

\begin{abstract}
Аннотация. Представлена обзорная характеристика процесса формирования приемлемого уровня проектной культуры у магистрантов направления подготовки «Социальнокультурная деятельность», обобщён многолетний авторский опыт преподавания соответствующих учебных дисциплин обучающимся Алтайского государственного института культуры (Барнаул, Россия). Проанализирована специфика проектного обучения в современных образовательных организациях высшего образования творческой направленности. Представлена авторская версия интерпретации содержания понятия «проектная культура», относящихся к категории междисциплинарных терминов. Проанализирован состав факторов, определяющих уровень проектной культуры субъекта социально-культурного проектирования. Представлены основные результаты диагностики уровня сформированности проектных компетенций магистрантов.

Ключевые слова: сочиально-культурная деятельность, проектная культура, проектная деятельность, социально-культурное проектирование, компетентностный подход, магистратура, инновачионные методы обучения в высшей школе.
\end{abstract}

Развитие социально-культурной сферы на современном этапе характеризуется трансформацией деятельности институтов, связанной с ростом индустрии знаний, формированием культуры инноваций, интенсификацией информационного обмена, активным использованием интерактивных цифровых технологий, организацией бесконтактного, дистанционного взаимодействия людей. Сфера культуры адаптируется к быстротекущим культурноисторическим и социально-экономическим процессам посредством разработки и реализации социально-культурных проектов. Широкое распространение практики социальнокультурного проектирования в нашей стране обуславливает переход к проектной системе управления социально-культурной деятельностью и актуализирует необходимость пересмотра используемых образовательных технологий в высших учебных заведениях страны. Эффективность подготовки будущих магистров в настоящее время обусловлена формированием у них проектной культуры.

Компетентностная парадигма, как базис развития современного образования, требует от высшей школы новаций в отношении подготовки специалистов, способных гибко реагировать на динамично изменяющиеся социально-культурные практики. Федеральный государ- 
ственный образовательный стандарт высшего профессионального образования 51.04.03 «Социально-культурная деятельность» предусматривает освоение выпускниками универсальных, общепрофессиональных и профессиональных компетенций, направленных на овладение навыками проектной деятельности. Данный тип задач профессиональной деятельности выпускника закреплен во второй универсальной компетенции (УК-2), первой общепрофессиональной компетенции (ОПК-1), и, как правило, в отдельных профессиональных компетенциях, определяемых участниками образовательного процесса. Магистранты должны научиться проектировать и реализовывать государственных программ по сохранению и развитию российской культуры, ее традиционных и инновационных форм, разработке и научному обоснованию социально-культурных проектов и программ, в экспертизе проектов социально-культурной направленности, проведении социально-культурного консалтинга, оказании консультационной помощи по разработке инновационных проектов и программ в социально-культурной сфере и другому [1].

Понятие «проектная культура» в начале XXI века получило широкое распространение в современной науке как междисциплинарная дефиниция. Этот термин имеет различное толкование, которое обусловлено контекстом проводимого конкретного научного исследования. Основой понимания данного явления является представление о проектной культуре как универсальной категории современного мышления, о проектировании как универсальном типе деятельности. Понятие «проектная культура» используется в области образования, культуры, искусства, в сферах социального обслуживания, организации быта и досуга, определении содержания отдельных видов деятельности, отражая при этом специфическую технологию, выступающую самостоятельным видом деятельности [2].

Использование данного термина в педагогической науке обусловлено широким распространением проектирования как эффективного инструмента обучения. Протообраз метода проектов в обучении начал использоваться с начала XX века до 1930-х годов. Дальнейшее развитие в различных педагогических теориях получил в 1970-х годах. К середине 1980-х годов получила распространение «внедренческая» концепция проектной деятельности, основанная на соотношения теории и практики [2; 3, с. 48]. В начале XXI века «в контексте педагогического проектирования стала разрабатываться проблема становления проектной культуры педагога и обучающихся» [4, с. 16], происходит осмысление проектной культуры будущего специалиста в условиях развития информационных систем и цифровизации [5, c. 201].

В педагогических исследованиях понятие проектная культура определяется как профессионально-личностное качество, формируемое в процессе подготовки в учреждении высшего образования, включающее совокупность знаний, умений и навыков, определяемых соответствующими компетенциями федерального государственного стандарта. В их числе особое место отводится умению находить решения творческих и организационных задач в нестандартных условиях, а также способности и готовности нести личную ответственность за результаты внедрения проектов [1]. «В проектной культуре реализуется искусство планирования, созидания, организации, исполнения, рефлексивного анализа и оценки достигнутого» [6].

В творческом вузе формирование проектной культуры осуществляется на основе технологии социально-культурного проектирования. Изучением проблем социально-культурного проектирования занимались Н. В. Апажикова, Г. М. Бирженюк, М. И. Долженкова, В. Ю. Дукельский, С. Э. Зуев, А. П. Марков, Г. В. Оленина, И. В. Соболева, О. В. Третьякова [7-14] и другие. Данный процесс имеет целью создание новой, отвечающей современным потребностям социума и отдельных групп потребителей среды (продукта), направлен на разработку и реализацию культурно-досуговых программ, технологий сохранения историкокультурного наследия и развития социально-культурного пространства, личности. Подчеркивая его значимость для развития российской культуры, авторы уделяют недостаточно внимания проблеме формирования проектной культуры у будущих профессионалов. 
Проектная культура магистрантов в творческом вузе рассматривается как основа инновационных преобразований социальных и культурных систем. Она имеет стратегическое значение в подготовке специалиста, соответствующего современным потребностям рынка труда, представляя собой сложную систему, охватывающую все подструктуры личности, позволяющую решать большую часть профессиональных задач. По определению Н. А. Запесоцкой, «структура проектной культуры включает личностный, технологический и информационный блоки. Составляющие личностного блока: а) ценностно-нормативный пласт (выступающий в качестве нравственной основы проектной деятельности); б) креативность; в) рефлексивность; в) коммуникативность; г) мотивация достижения. Технологическая группа включает в себя: мыслительные техники (связанные с использованием аналитических, творческих способностей, основанных на развитом критическом мышлении); коммуникативную компетентность; игровую культуру проектировщика. Информационный блок содержит типовые модели ситуации, характеристику нормативных состояний объектов, описание проектного потенциала различных видов социально-культурной коммуникации, проектные решения в различных сферах» [15]. Сущность проектирования магистрантов направления подготовки «Социально-культурная деятельность» заключается в создании новых социальнопедагогических условий с заданными свойствами, предполагающих трансформацию социально-культурного пространства.

Развитие проектной культуры у магистрантов Алтайского государственного института культуры осуществляется в рамках аудиторной (дисциплины - «Управление проектами», «Практикум социально-культурного проектирования», «Технологии менеджмента инноваций», «Технологии организации деятельности учреждений культуры социально-культурной сферы») и самостоятельной работы, а также в период прохождения практик (учебной (проектно-технологической) практики, производственной практики (научно-исследовательская работа)) в условиях инновационно-развивающей среды учреждения культуры (образования). Использование технологии социально-культурного проектирования в процессе подготовки магистров социально-культурной деятельности способствует:

- развитию мышления обучающегося (аналитического, критического, творческого, проектного);

- повышению у них мотивации к обучению;

- стимулированию формирования навыков: поиска информации, ее анализа, использования в практической деятельности, в том числе для создания новых объектов (свойств объектов);

- увеличению эффективности самостоятельной работы обучающихся;

- формированию важнейших компетенций;

- улучшению качества образования.

Педагогические технологии формирования проектной культуры обучающихся в вузах культуры неоднократно обсуждались на научных и научно-практических мероприятиях различного уровня. Результаты работы ученых, педагогов были опубликованы в журналах, сборниках статей и других изданиях. В качестве наиболее эффективных были признаны презентация, тренинг, мастер-класс, кейс-стади, проектирование, семинар-диспут, имитационные и деловые игры, коллоквиум, создание проектных команд и другие [15-20].

Основная задача обучающегося - усвоение знаний. Вместе с тем, информация сегодня обладает неустойчивостью. Поэтому магистрант должен выработать навыки, необходимые современному специалисту в условиях развития информационного общества, связанные с поиском необходимых данных, их анализом, обработкой, применением, созданием на их основе новой информации. Социально-культурное проектирование обладает значительным потенциалом для подготовки специалиста высшей квалификации в сфере культуры, поскольку базируется на последовательном выполнений действий, включающем:

- «выявление актуальной проблемы развития социально-культурной сферы;

- определение концепции проекта; 
- формулирование целей и задач проекта;

- подсчет материальных ресурсов проекта;

- анализ информационных ресурсов проекта;

- анализ кадровых ресурсов проекта;

- разработку плана проекта;

- реализации комплекса мероприятий, предусмотренных проектом;

- оценку результатов реализации проекта

- оформление сопровождающей документации» [16, с. 146].

Одним из наиболее важных компонентов, оказывающих влияние на эффективность обучения, является мотивация. Проектирование в данном аспекте дает возможность свободного выбора проблемы, содержания деятельности, социально-культурных технологий, актуализируя потребность к профессиональному самовыражению и самоопределению обучающегося. Реализация социально-культурного проекта позволяет развивать значительный диапазон способностей личности: от творческих до организаторских. Опыт воздействия на социальнокультурное пространство повышает самооценку, веру в собственные профессиональные знания, умения и навыки, мотивирует к продолжению проектной деятельности.

«В процессе формирования проектной культуры центральное место занимает создание внутривузовской конкурентной среды. Данное направление работы дополнительно способствует повышению мотивации обучающихся, а также улучшению качества проектов. Конкурентная среда, образованная в результате ежегодного проведения конференций, конкурсов и иных научных и творческих мероприятий различного уровня, позволяет выявить реальные достижения обучающегося и соотнести их с успехами других. Ежегодно в Алтайском государственном институте культуры проводятся межрегиональная (с международным участием) научно-практическая студенческая конференция «Развитие социально-культурной деятельности и художественного образования», международная научно-практическая конференция молодых ученых, аспирантов и соискателей «Инновационные технологии в гуманитарной сфере», секции городской научно-практической конференции молодых ученых «Молодежь Барнаулу», где каждый обучающийся может презентовать авторские научные, творческие, социальные идеи и проекты» [16, с. 147].

Конкуренция в образовательной среде вуза достаточно высока. Ежегодно обучающимися в Алтайском государственном институте культуры создаются более 200 проектов. «Систематизация проектной деятельности института позволяет выделить следующие типы:

- научно-исследовательские - приближенные к научному исследованию, содержащие доказательство актуальности, предмет, объект, задачи, гипотезы исследования, обозначение методов, источников информации, обобщение результатов, выводы, оформление результатов, постановку новых проблем;

- творческие - не имеющие детально проработанной структуры, подчиняющиеся жанру конечного результата (спектакль, концерт, праздник и др.), но имеющие результат, оформленный в продуманной завершённой форме (сценарий спектакля или праздника, программа концерта и др.);

- информационные - связанные со сбором информации и ознакомлением с ней заинтересованных лиц, анализом и обобщением фактов, созданием баз данных;

- социально-культурные - ориентированные на результат деятельности в интересах какой-либо группы людей, развития социокультурного пространства региона, требующие распределения функций участников, плана действий, экспертизы» [16, с. 147].

С 2014 года вузом проводится конкурс инновационных проектов обучающихся. Обучающиеся ежегодно соревнуются за главный приз ректората Алтайского государственного института культуры - средства для реализации авторского проекта.

Ежегодно магистрантами направления подготовки «Социально-культурная деятельность» на конкурс подаются от 3 до 7 проектов. С 2014 по 2021 гг. можно отметить стабиль- 
ный интерес обучающихся к разработке и реализации инновационных программ воспитания. Решению данной проблемы посвящено 10 проектов. Проведению социально-культурных акций -5 . Изданию информационных материалов -1 . Научному обсуждению теоретической проблемы - 1. Значительная часть из представленных на конкурс работ получила высокие оценки экспертной комиссии. Средний балл составил 72 из 80 возможных. 4 проекта были рекомендованы для участия в региональных конкурсах грантов. 5 проектов приняли участие в конкурсах федерального уровня.

Анализ содержания заявок показал, что технические и качественные недоработки имеют отдельные из их числа. Большая часть ошибок в проектировании связана с сопоставлением цели и запрашиваемого финансирования. Для повышения качества оформления заявок ежеквартально проводятся семинары, мастер-классы и иные обучающие занятия.

Уровень сформированности проектной культуры диагностировался автором в рамках мониторинга результатов обучения магистрантов в форме беседы. Опрос проводился в 2 этапа - перед началом обучения в магистратуре и после его окончания. Сроки исследования 2019-2021 гг. В опросе приняли участие 17 магистрантов очной и заочной форм обучения. 100 процентов опрошенных составили молодые люди 18-35 лет, каждый из которых (100\%) знает о том, что такое социально-культурный проект. При этом 61 \% опрошенных на первом этапе (сентябрь 2019, сентябрь 2020 г.) не имели опыта разработки собственного проекта, у $26 \%$ - имелся один, а у $13 \%$ - более одного проекта в активе. Содержание проектов, разработанных обучающимися, варьировались: от создания музыкального фестиваля до повышения эффективности деятельности любительского хореографического коллектива, от организации клуба любителей исторической реконструкции до передвижной школы искусств, т. е. проектировались различных по масштабам, форме видов социально-культурной деятельности.

Самым трудным в проектировании магистранты считали поиск креативной идеи для проекта (66 \%), также сложным считается написание текста проекта (13\%), формирование мотивации к работе над собственным социально-культурным проектом (13\%), разработка сметы (86 \%) и создание команды $(13 \%)$. Ответы на вопрос о том, что уже было предпринято для решения проблем с написанием проекта, распределились следующим образом: большинство участников опроса самостоятельно ищут ответы и решения (60\%), чуть меньшая аудитория отметила, что просто не знает, что с этим делать (13\%) или ничего не делает (6\%). Значительная часть опрошенных (46 \%) получила знания о социально-культурном проектировании во время освоения дисциплин бакалавриата, на курсах, семинарах, мастерклассах в очном или заочном формате.

На втором этапе 100 \% опрошенных имели опыт социально-культурного проектирования и собственные разработанные проекты. Магистранты отметили, что самым важным в проектной деятельности считают умение создавать оригинальные идеи, презентовать и преобразовывать их в текстовый формат $(60 \%)$. На втором месте по значимости стоит получение опыта проектной деятельности (53\%). Третье место занял ответ «создать команду единомышленников» (40 \%). Поровну (по 20 \%) разделились варианты ответов «найти с помощью проекта хорошую работу» и «создать с помощью проекта некоммерческую организацию». Уровень собственной проектной грамотности магистранты оценили в среднем на 8-9 баллов по десятибалльной шкале, что свидетельствует о хорошем уровне сформированности проектной культуры в конце обучения.

Анализ ответов на вопросы теоретического блока в начале и в конце обучения продемонстрировал положительную динамику уровня владения проектными компетенциями. Магистранты обозначали проблемные области, нуждающиеся в проектировании, стратегические направления инновационного развития социально-культурной сферы, указывались риски реализации проектов.

Таким образом, развитие проектной культуры магистра направления подготовки «Социально-культурная деятельность» происходит посредством использования современных 
образовательных технологий при изучении теоретических дисциплин в процессе аудиторной и самостоятельной работы, а также при прохождении практики в учреждениях социальнокультурной сферы. Мотивация обучающихся к проектной деятельности, стимулируемая как внутренней, так и внешней средой творческого вуза, достаточно высока. Мониторинг сформированности проектных компетенций свидетельствует об эффективности применения технологии социально-культурного проектирования, основанной на научном анализе проблемной ситуации, знании механизмов решения задач, в том числе инновационных, теории и практике управления проектами.

\section{Сиисок литературы}

1. Об утверждении федерального государственного образовательного стандарта высшего образования по направлению подготовки 51.04.03 Социально-культурная деятельность (уровень магистратуры) : приказ Министерства образования и науки Российской Федерации от 14 дек. 2015 г. № 1465 // Портал Федеральных государственных образовательных стандартов высшего образования : [сайт]. - Москва, 2021. - URL: http://gosvo.ru/uploadfiles/fgosvom/510403.pdf (дата обращения: 15.11.2021).

2. Филимонюк, Л. А. Формирование проектной культуры педагога в процессе профессиональной подготовки : автореф. ... дисс. д-ра пед. наук : 13.00.08. - Ставрополь, 2008. - 42 с.

3. Филимонюк, Л. А. Культурно-исторические предпосылки исследования проблемы проектной культуры // Вестник Северо-Кавказского государственного технического университета. - 2006. - № 4. - C. $48-52$.

4. Тихонова, А. Ю. Формирование проектной культуры у магистров в условиях практикоориентированной профессиональной подготовки / А. Ю. Тихонова, Н. М. Новичкова // Мир науки, культуры, образования. - 2015. - № 1. - С. 16-20.

5. Натус, Н. И. Формирование проектной культуры будущих специалистов средствами цифровизации // Образование: Ресурсы развития. Вестник ЛОИРО. - Санкт-Петербург : [б. и.], 2020. - № 1. C. 85-87.

6. Полат, Е. С. Личностно-ориентированные технологии обучения // 12-летняя школа. Проблемы и перспективы развития общего среднего образования/ под ред. В. С. Леднева, Ю. И. Дика, А. В.Хуторского. - Москва : ИОСО РАО, 1999.- 226 с.

7. Апажикова, Н. В. Социокультурное проектирование как одно из ведущих направлений в сфере дополнительного образования / Н. В. Апажикова, М. И. Долженкова // Вестник Тамбовского университета. Серия: Гуманитарные науки. - 2017. - Т. 22, вып. 4. - С. 30-36.

8. Дудченко, В. С. Инновационные игры: методология и методика // Социальное проектирование в сфере культуры: игровые методы : сб. науч. ст. - Москва : НИИ культуры, 1988. - С. 103-112.

9. Дукельский, В. Ю. Культурный проект: от замысла к реализации // Музей будущего: информационные технологии и культурное наследие : [сайт]. - Москва, 2000-2014. - URL: http://www.future.museum. ru/part01/010301.htm (дата обращения: 15.11.2021).

10. Зуев, С. Э. Социально-культурное проектирование : [сб. учеб.-метод. матер.]. - Ижевск : Альтернатива, 2003. - $156 \mathrm{c.}$

11. Марков, А. П. Основы социально-культурного проектирования: учеб. пособие / А. П. Марков, Г. М. Бирженюк. - Санкт-Петербург : Изд-во СПбГУП, 1998. - 364 с.

12. Оленина, Г. В. Развитие самоуправления студенческой молодёжи в сфере досуга на основе проектного подхода: теория и практика // Мир науки, культуры, образования. - 2010. - № 2. C. $99-103$.

13. Социально-культурное проектирование : учеб.-метод. комплекс / сост. О. В. Третьякова. Тюмень : Тюменская гос. акад. культуры, искусств и соц. технологий, 2010. - 45 с.

14. Селевко, Г. К. Энциклопедия образовательных технологий : [в 2 т.]. - Т. 1. - Можайск (Моск. обл.) : Можайский полиграфкомбинат, 2006. - 816 с. : ил., табл.

15. Запесоцкая, Н. А. Проектная культура как основа профессионального мастерства менеджера социально-культурной сферы : автореф. дисс. ... канд. пед. наук: 13.00.05. - Санкт-Петербург, 2007. $10 \mathrm{c}$.

16. Олейник, Я. А. Проектная деятельность обучающихся как средство повышения качества образования в Алтайской государственной академии культуры и искусств // Качество образования 
в сфере культуры и искусств в условиях реализации ФГОС ВО : сб. матер. XV всерос. науч.-метод. конф. (с междунар. участием). - Барнаул : Изд-во Алт. гос. ин-та культуры, 2015. - С. 145-148.

17. Неусыпова, Е. А. Методические подходы к развитию проектного мышления будущих деятелей социально-культурной сферы в вузах культуры и искусства // Научное мнение. - 2020. - № 6. C. 120-124. - DOI: https://doi.org/10.25807/PBH.22224378.2020.6.119.125.

18. Бондарчук, Д. А. Реализация социально-педагогических возможностей проектного подхода в вузе культуры // Современный учёный. - 2021. - № 5. - С. 27-30.

19. Горбачёва, Д. А. Инновационная проектная деятельность при социальной адаптации студентов (на примере Краснодарского государственного института культуры)/ Д. А. Горбачёва, А. А. Горбачёв, Г. С. Сазыка // Курорты. Сервис. Туризм. - 2017. - № 1-2. - С. 155-164.

20. Чиркина, Р. В. Оценка проектной культуры студентов в процессе освоения технологий социального проектирования // Психология и право. - 2016. - № 4. - С. 209-223. - DOI: 10.17759/psylaw.2016060419.

Yana A. Ivonina, Ph. D. in History, Associate Professor Altai State Institute of Culture (Barnaul, Russia) yana-ol@mail.ru

\title{
DEVELOPMENT OF PROJECT CULTURE OF MASTER'S DEGREE STUDENTS OF TRAINING PROGRAM "SOCIAL AND CULTURAL ACTIVITIES" (A CASE OF ALTAI STATE INSTITUTE OF CULTURE (BARNAL, RUSSIA))
}

\begin{abstract}
The paper gives a review of process of developing acceptable level of project culture of master's degree students of program "Social and Cultural Activities", disclose the author's long-term experience in teaching match disciplines in Altai State Institute of Culture (Barnaul, Russia). The specifics of social and cultural designing education in the today's educational institutions of higher education are clarified. The author explains her own view on a term "project culture" that is in class of multi-disciplinary concepts. Also, the paper analyses a number of factors that define a level of project culture of an actor of social and cultural designing. Key results of diagnostics of a level of formedness of master's degree students' project competencies are presented.

Keywords: social and cultural activities, project culture, project activity, social and cultural designing, competence-based approach, master's degree program, innovative methods of training in higher educational institutions.
\end{abstract}

УДК [378.1:008(470+571)]:004

DOI: $10.32340 / 2414-9101-2021-4-59-64$

Р. В. Ильин

Алтайский государственный институт культуры (Барнаул, Россия) rvi22@mail.ru

\section{ИЗ ОПЫТА ВНЕДРЕНИЯ ЦИФРОВЫХ ТЕХНОЛОГИЙ В ОБРАЗОВАТЕЛЬНЫЙ ПРОЦЕСС ТВОРЧЕСКОГО ВУЗА}

Аннотация. Охарактеризована эволюция методологических и методических подходов к массовому внедрению цифровых технологий в различные сферы жизни и производства, сложившихся в отечественной науке и философии с конца 1980-х до начала 1990-х гг. Со ссылкой на Стратегию государственной культурной политики на период до 2030 г. (2016 г.) автор аргументирует необходимость обращения к передовым информационнотелекоммуникационным технологиям для решения тактических и перспективных социокультурных задач, стоящих перед российским государством. Изложен авторский взгляд 